\title{
Introducing Pay-for-Performance within Hong Kong's Public Hospitals
}

\author{
Koon Hung Lee*, Steve Gillett \\ From 26th Patient Classification Systems International (PCSI) Working Conference \\ Munich, Germany. 15-18 September 2010
}

\section{Introduction}

The Hong Kong Hospital Authority (HA) manages 41 publicly funded hospitals that serve approximately $90 \%$ of the seven-million population. The head office of HA is responsible for strategic planning, resources allocation, and monitoring performance of hospitals that are organized into seven geographical clusters. The head office is transforming its population-based internal resources allocation system to a Pay-for-Performance (P4P) system using case mix as a currency for strategic purchasing, as well as a performance measurement tool.

\section{Methods}

Prior to financial year 2009-10, HA allocated funding to clusters based upon a historical budget approach that was largely built upon an age-adjusted population-based model implemented in 2003-04. Hospital funding growth was curbed as a result of the poor fiscal condition of the HK government between 2003-2006. The hospital services were outdated, and there was little incentive to promote productivity and quality; hence, the waiting time was prolonged.

In 2009-10 HA introduced a new P4P hospital-funding model with budget attached to service growth in strategic priority areas such as cancer, renal dialysis, new facilities, and programmes that improve service quality and modernization. A DRG-based case-mix model was developed to measure hospital performance and to guide the hospital clusters' baseline budget adjustment. The model was also used to allocate funding growth to strategically purchase services most needed by the community from hospital clusters, based upon the case-mix price.

\section{Results}

Approximately HK\$ $872 \mathrm{Mn}$, representing 2-4\% of funding growth, was given to the seven hospital clusters for 2009-10. Approximately $60 \%$ was allocated for service growth, and the rest for quality and service improvement. By the end of March 2010, acute inpatient activities increased by $7.5 \%$. There was also a dramatic increase in coded activities, with 'coding creep' contributing to $12 \%$ among the $20 \%$ increase in weighted episodes. The ALOS per episode was reduced by $6.7 \%$. A 'pay-for-quality' incentive program is being developed for $2010 / 11$.

\section{Conclusions}

This paper gives an overview of HA's P4P and describes its impact in the first year, with substantial growth in acute admissions and DRG-weighted episodes. It outlines the difficulties and challenges encountered during implementation and discusses clinician responses to the change and the new 'pay-for-quality' program.

Published: 6 October 2010

doi:10.1186/1472-6963-10-S2-A17

Cite this article as: Lee and Gillett: Introducing Pay-for-Performance within Hong Kong's Public Hospitals. BMC Health Services Research 2010 10(Suppl 2):A17.

Hong Kong Hospital Authority, Mongkok, Hong Kong 